\title{
Evaluasi Kondisi Lingkungan Akuakultur Pada DAS Tondano \\ Di Kelurahan Ternate Baru Kota Manado
}

(Evaluation of The Environmental Conditions of Aquaculture on The Watershed in Tondano River of Ternate Baru Manado)

\author{
Dolvinus Wakman ${ }^{1}$, Suzanne L. Undap ${ }^{2}$, Indra Salindeho ${ }^{2}$ \\ ${ }^{1)}$ Mahasiswa Program Studi Budidaya Perairan FPIK UNSRAT Manado \\ 2) Staf pengajar pada Program Studi Budidaya Perairan FPIK UNSRAT Manado \\ Email: suzanne.undap@gmail.com
}

\begin{abstract}
In this study, we evaluated the current condition of the environmental conditions of aquaculture on watershed Tondano River in terms of physical and chemical parameters. Determination of sampling points at each station is placed vertically at three predetermined points from the brigde toward the front of the aquaculture, the distance between one point to the next point was $\pm 50 \mathrm{~m}$; whereas for the analysis of water quality parameters was done using an HORIBA water quality meters type U-536. Determination points were done by purposive sampling which refers to the physiographic location wherever possible in order to represent or describe these waters. The research was carried out for 3 weeks and was done in 3 stages, morning, afternoon and evening. For direct measurement (in situ) was performed once a week at the three points which included parameters $\mathrm{pH}$, temperature, conductivity, DO, Oxidation reduction potential, turbidity, TDS, depth and GPS. Generally, the result of water quality analysis at the aquaculture still in the water quality standard PP No.82 of 2001.
\end{abstract}

Keywords: Evaluation, water quality, water Lake Tondano, Aquaculture

\section{PENDAHULUAN}

Akuakultur atau budi daya perikanan saat ini telah menjadi industri yang berkembang pesat karena adanya peningkatan permintaan yang signifikan untuk memenuhi gizi manusia. Dalam usaha pengembangan akuakultur seperti pembudidayaan ikan, daerah aliran sungai (DAS) merupakan salah satu sumber daya alam yang bisa dimanfaatkan, seperti DAS Tondano yang hulunya berada di Danau Tondano (Fardiansyah, 2011).
Sungai Tondano adalah satu satunya outlet dari Danau Tondano yang mempunyai luas total 466,4 km2 yang mengalir sepanjang 44,4 $\mathrm{km}$ yang bermuara di teluk Manado (Onibala, 2008). Berdasarkan kondisi ini maka sungai Tondano merupakan sumber daya perairan yang strategis bagi akuakultur dan pembangunan perekonomian di Provinsi Sulawesi Utara.

Beberapa tahun terahir ini, sungai Tondano telah mengalami degradasi lingkungan. Perubahan ini mengakibatkan 
penurunan kualitas air DAS Tondano disebabkan oleh kegiatan pertanian, peternakan, pembuangan sampah dan kegiatan MCK masyarakat serta kegiatan usaha perikanan yaitu budi daya ikan.

Budi daya ikan dalam karamba di Sungai Tondano memiliki potensi yang cukup besar dan strategis untuk pengembangan usaha budi daya karamba. Salah satu daerah yang dekat dengan muara Sungai Tondano yang telah mengembangakan usaha budi daya karamba adalah Kelurahan Ternate Baru. Usaha ini telah dijalankan sejak tahun 1981 sampai sekarang. Tetapi masalah yang selalu timbul dalam sistem budi daya perairan adalah pencemaran air di lingkungan DAS, berupa pencemaran fisika kimia perairan yang dapat menggangu usaha budi daya karamba di lokasi ini, apalagi setelah dilakukan evaluasi jumlah petani pembudidayaan ikan di Kelurahan Ternate Baru saat ini sudah sangat berkurang jika dibandingkan sebelum terjadinya banjir bandang di Manado pada awal tahun 2014.

Berkaitan dengan masalah di atas, maka dalam penelitian ini dilakukan evaluasi kondisi lingkungan akuakultur di DAS Tondano yang terletak di Kelurahan Ternate Baru Kota Manado. Oleh karena itu, evaluasi ini menggunakan data sekunder pada beberapa tahun terakhir yang sudah ada berupa data parameter fisika kimia kualitas air dan dibandingkan dengan data primer yakni suhu, kekeruhan, derajat keasaman $(\mathrm{pH})$, oksigen terlarut (DO), Total Padatan Terlarut (TDS), Daya Hantar Listrik (DHL) dan Oxidation Reduction Potential (ORP)/ Redoks potensial. Penelitian dilakukan selama 3 bulan, yaitu bulan November 2014 sampai Januari 2015.

\section{METODE PENELITIAN}

Kegiatan penelitian ini terdiri dari pengukuran sampel langsung di lapangan (in situ) dan menganalisis hasil pengukuran secara deskriptif. Kondisi lingkungan adalah parameter kualitas air yang diukur berupa suhu, derajat keasaman ( $\mathrm{pH})$, DO (Dissolve oxygen/ oksigen terlarut), ORP (Oxidation Reduction Potential), konduktivitas, kekeruhan dan TDS (Total Dissolved Solid/ total padatan terlarut). Penentuan pengukuran parameter kualitas air ini disesuaikan dengan fasilitas alat HORIBA U-536 yang digunakan

\section{Analisis Data}

Data yang diperoleh dan dikumpulkan dalam penelitian ini berupa data primer yakni, pengukuran parameter kualitas air yang diukur secara in situ (suhu, pH, DO, kekeruhan dll). Data primer ini dianalisis secara deskriptif dan ditampilkan dalam bentuk tabel kemudian dibandingkan dengan menggunakan Baku Mutu PP (Peraturan Pemerintah) Nomor 82 Tahun 2001, Tentang Pengelolaan Kualitas Air dan Pengendalian Pencemaran Air serta kriteria-kriteria untuk kegiatan budidaya serta kesehatan ikan di perairan.

Data sekunder (data pendukung) berasal dari hasil analisis laboratorium yang dilakukan oleh peneliti terdahulu pada lokasi penelitian yang sama untuk mendapatkan gambaran selama beberapa tahun. Data sekunder juga diperoleh dari berbagai sumber seperti dari laporanlaporan hasil penelitian terdahulu yang berhubungan dengan topik yang diteliti. 


\section{HASIL DAN PEMBAHASAN}

Pada penelitian ini menggunakan dua jenis data hasil parameter kualitas air yaitu, data primer: pengukuran secara langsung (in situ) meliputi suhu, kekeruhan, konduktivitas, DO, pH, TDS dan ORP di lokasi penelitian (Tabel 1) dan data sekunder merupakan hasil penelitian yang dilakukan oleh Rompas (2002), Lensun dan Tumembouw (2013), seperti yang tersaji pada Tabel 2.

\section{Evaluasi Kondisi Lingkungan Budi daya}

Oksigen Terlarut (DO)

Hasil pengukuran kandungan oksigen terlarut (DO) di DAS Tondano Kelurahan Ternate Baru Kota Manado pada semua titik sampling di berkisar antara 2,14 - 5,70 mg/L dengan menggunakan alat HORIBA. Hasil evaluasi pengukuran DO (3,83 - 4,44 mg/L) di Kelurahan Ternate Baru Kota Manado tidak terlalu jauh seperti dilaporkan oleh Rompas (2002) yang juga menggunakan alat HORIBA.

Berdasarkan hasil penelitian Lensun dan Tumembouw, 2013 yang dilaksanakan pada bulan Januari - Maret 2012, nilai DO berkisar antara 6,3 - 7,5 mg/L. Rompas (2002), kandungan DO adalah 3,83 - 4,44 mg/L. Sedangkan sebaran nilai DO pada hasil penelitian ini antara 2,14 - 5,70 mg/L. Nilai DO mengalami trend penurunan dibandingkan dengan hasil penelitian yang terdahulu. Hal ini menunjukkan bahwa di DAS Tondano Kelurahan Ternate Baru Kota Manado tingkat kesegaran air pada tahun 2014 mengalami penurunan jika dibandingkan dengan tahun 2002 dan
2013, disamping itu banjir badang yang terjadi pada Januari 2014 menyebabkan kualitas air di lokasi penelitian ini memburuk.

Dari hasil pengukuran DO pada penelitian ini, kandungan oksigen tertinggi terukur pada Titik 3 di waktu sore hari (17.00-19.00) yaitu $5,70 \mathrm{mg} / \mathrm{L}$ dan terendah (2,14 $\mathrm{mg} / \mathrm{L})$ terukur pada pagi hari (07.00-09.00) pada Titik 1 dan 2. Hal ini sesuai dengan pendapat Boyd, 1988 dalam Effendi, 2003 yang menyatakan bahwa kadar oksigen terlarut maksimum terjadi pada sore hari, sedangkan kadar minimum terjadi pada pagi hari.

Kandungan oksigen terlarut di Titik 1 dan Titik 2, di mana berada dekat dengan rumah penduduk dan aktivitas budi daya menunjukkan nilai DO terendah yaitu 2,14 mg/L. Kondisi ini tergolong tidak layak berdasarkan Baku Mutu Air sesuai PP. No. 82 Tahun 2001 tentang Pengelolaan Kualitas Air dan Pengendalian Pencemaran kelas III, di mana disyaratkan batas minimum untuk budi daya adalah $3 \mathrm{mg} / \mathrm{L}$. Sehingga dapat dinyatakan bahwa kandungan DO tidak berada pada kondisi alami yaitu pada batasan minimum $<3 \mathrm{mg} / \mathrm{L}$.

Kordi dan Tancung (2007), kandungan oksigen terlarut yang baik untuk budi daya ikan adalah antara 5- 7 mg/L, sedangkan sebaran oksigen terlarut pada hasil penelitian ini antara 2,14 - 5,70 $\mathrm{mg} / \mathrm{L}$. Hal ini menunjukkan kandungan oksigen terlarut secara umum di areal budi daya DAS Tondano ini sudah tercemar oleh bahan organik yang mudah terurai dan tidak layak lagi untuk usaha budi daya ikan. 
Tabel 1. Data primer pengukuran in situ parameter kualitas air

\begin{tabular}{|c|c|c|c|c|c|c|c|c|c|c|}
\hline & \multirow{2}{*}{ Parameter } & \multicolumn{3}{|c|}{ Pagi (07.00-09.00) } & \multicolumn{3}{|c|}{ Siang (12.00-14.00) } & \multicolumn{3}{|c|}{ Sore $(17.00-19.00)$} \\
\hline & & Titik 1 & Titik 2 & Titik 3 & Titik 1 & Titik 2 & Titik 3 & Titik 1 & Titik 2 & Titik 3 \\
\hline \multirow{7}{*}{ 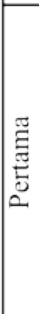 } & Suhu $\left({ }^{\circ} \mathrm{C}\right)$ & 27,07 & 27.1 & 27,7 & 28.0 & 28,02 & 28.02 & 28,0 & 28.0 & 28,1 \\
\hline & Kekeruhan & 30,2 & 30.2 & 30,2 & 30,2 & 30.2 & 30,2 & 30,2 & 30.2 & 30,2 \\
\hline & $\begin{array}{l}\text { Konduktivitas } \\
\text { m.S cm) }\end{array}$ & 0.221 & 0.218 & 0.216 & 0.221 & 0.218 & 0.216 & 0.221 & 0.218 & 0.216 \\
\hline & TDS (g/L) & 0.143 & 0.142 & 0.140 & 0.143 & 0.142 & 0.140 & 0.143 & 0.142 & 0.140 \\
\hline & $\mathrm{pH}$ & 5,10 & 7,07 & 7,10 & 5.19 & 7,11 & 6,90 & 6.19 & 6,14 & 6,09 \\
\hline & DO & 4,44 & 4,06 & 5,03 & 4,04 & 4,01 & 5,21 & 4,14 & 4,08 & 5,70 \\
\hline & $\mathrm{ORP}^{*}(\mathrm{mV})$ & 270 & 184 & 185 & 270 & 184 & 185 & 270 & 184 & 185 \\
\hline \multirow{7}{*}{ 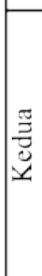 } & Suhu & 27,23 & 27,7 & 27,36 & 28.6 & 28,8 & 28.1 & 27,2 & 28.6 & 28,5 \\
\hline & Kekeruhan & 30,8 & 30,8 & 30,8 & 30,8 & 30,8 & 30,8 & 30,8 & 30,8 & 30,8 \\
\hline & Konduktivitas & 0.23 & 0.22 & 0.23 & 0.23 & 0.22 & 0.23 & 0.23 & 0.22 & 0.23 \\
\hline & TDS & 0.143 & 0.142 & 0.140 & 0.143 & 0.142 & 0.140 & 0.143 & 0.142 & 0.140 \\
\hline & $\mathrm{pH}$ & 5,10 & 7,17 & 7,06 & 5,10 & 7,01 & 7,06 & 5,10 & 7,17 & 7,06 \\
\hline & DO & 2,14 & 2,14 & 4,57 & 2,14 & 2,14 & 4,57 & 2,14 & 2,14 & 4,57 \\
\hline & ORP & 270 & 184 & 185 & 191 & 181 & 166 & 191 & 174 & 176 \\
\hline \multirow{7}{*}{ | } & Suhu & 27,4 & 27.8 & 27,8 & 28.0 & 28,0 & 27.9 & 27,6 & 27.4 & 28,2 \\
\hline & Kekeruhan & 30.67 & 30.21 & 30.49 & 30.67 & 30.67 & 30.21 & 30.49 & 30.67 & 30.67 \\
\hline & Konduktivitas & 0.23 & 0.22 & 0.23 & 0.23 & 0.22 & 0.23 & 0.23 & 0.22 & 0.23 \\
\hline & TDS & 0.143 & 0.143 & 0.143 & 0.143 & 0.143 & 0.143 & 0.143 & 0.143 & 0.143 \\
\hline & $\mathrm{pH}$ & 5,08 & 7,10 & 7,02 & 5.19 & 7,10 & 6,19 & 5.04 & 6,41 & 6,59 \\
\hline & DO & 4,51 & 4,4 & 5,07 & 4,51 & 4,4 & 5,07 & 4,51 & 4,4 & 5,07 \\
\hline & ORP & 270 & 184 & 185 & 191 & 181 & 166 & 191 & 174 & 176 \\
\hline
\end{tabular}

Tabel 2. Evaluasi hasil pengukuran parameter fisika kimia air di lokasi penelitian

\begin{tabular}{|l|c|c|c|c|}
\hline \multirow{2}{*}{ Parameter (Satuan) } & \multirow{2}{*}{$\begin{array}{c}\text { Data Primer } \\
(2014)\end{array}$} & \multicolumn{2}{|c|}{ Data Sekunder } & \multirow{2}{*}{ Baku Mutu*** } \\
\cline { 3 - 4 } & & $2002^{*}$ & $2013^{* *}$ & \\
\hline DO (mg/L) & $2,14-5,70$ & $3,83-4,44$ & $6,3-7,5$ & $>3$ \\
\hline Suhu $\left({ }^{\circ} \mathrm{C}\right)$ & $27,01-28,8$ & $26,2-29,6$ & $27-27,8$ & Deviasi 3 \\
\hline Kekeruhan (NTU) & $30,20-30,80$ & $12-15$ & $37,9-150$ & - \\
\hline pH & $5,10-7,17$ & $6,00-6,77$ & - & $6-9$ \\
\hline
\end{tabular}

Sumber: *Rompas (2002); **Lensun dan Tumembouw (2013); ***PP No. 82 tahun 2001 tentang Pengelolaan Kualitas Air (kelas III: perikanan pembudidayaan ikan air tawar)

Suhu

Hasil pengukuran in situ, ketiga titik menunjukkan bahwa suhu berada pada kisaran antara $27,01-28,8^{\circ} \mathrm{C}$ dimana nilai terendah $\left(27,01^{\circ} \mathrm{C}\right)$ berada di titik I pada pagi hari (07.00-09.00) dan $\left(28,8^{\circ} \mathrm{C}\right)$ nilai tertinggi, berada di titik 2 pada siang hari (12.00-14.00). Menurut Effendi (2003), Suhu $23^{\circ}-32^{\circ} \mathrm{C}$ merupakan suhu yang cocok untuk pemeliharaan ikan 
dalam kegiatan budi daya. Namun demikian ikan di daerah tropis seperti di Manado dapat hidup dengan baik pada kisaran suhu $30^{\circ}-35^{\circ} \mathrm{C}$ (Kordi dan Tancung, 2007). Berdasarkan baku mutu kualitas air menurut PP No. 82 Tahun 2001, suhu berdeviasi 3 di lokasi penelitian masih normal sesuai keadaan alami daerah di Manado.

$$
\text { Kordi dan Tancung (2007) }
$$
menyatakan bahwa suhu optimal bagi kehidupan ikan diperairan tropis adalah berkisar antara $28^{\circ} \mathrm{C}-32^{\circ} \mathrm{C}$. Pada kisaran tersebut konsumsi oksigen akan mencapai $2,2 \mathrm{mg} / \mathrm{g}$ berat tubuh/jam. Apabila dibawah suhu $25^{\circ} \mathrm{C}$, konsumsi oksigen mencapai $1,2-18^{\circ} \mathrm{C}$ mulai berbahaya bagi ikan sedangkan dibawah $12^{\circ} \mathrm{C}$ ikan tropis akan mati kedinginan. Secara teoritis ikan tropis masih dapat hidup normal pada suhu $30-35^{\circ} \mathrm{C}$ apabila konsentrasi oksigen terlarut cukup tinggi.

\section{Kekeruhan}

Hasil pengukuran secara langsung di lapangan (in situ), ketiga titik diperoleh nilai kekeruhan terendah 30,2 NTU. Sedangkan nilai tertinggi 30,80 NTU berada pada pengukuran kedua di semua titik sampling, yaitu Titik 1, II dan III.

Boyd (1982) menyatakan bahwa kisaran kekeruhan yang baik dalam kegiatan usaha budi daya ikan sebaiknya berkisar antara 2-30 NTU. Sedangkan nilai kekeruhan pada penelitian ini adalah diatas 30 NTU. Oleh karena itu secara umum nilai kekeruhan yang diperoleh dari ketiga Titik sampling berada dalam kondisi tidak layak untuk kriteria budi daya ikan. Akibat kekeruhan yang tinggi dapat mengganggu system pernafasan dan daya lihat biota akuatik serta dapat menghambat penetrasi cahaya ke dalam air (Effendi, 2003)

\section{Derajat Keasaman (pH)}

Dari hasil pengukuran secara langsung pada ketiga titik penelitian, nilai $\mathrm{pH}$ berkisar. Nilai $\mathrm{pH}$ tertinggi $(7,17)$ terukur pada Titik II di siang hari dan terendah $(5,10)$ terukur pada Titik I di pagi, siang dan sore hari. Kondisi ini cenderung tidak sesuai dengan batas standar baku mutu air (pH 6-9) PP No. 82 Tahun 2001 kelas III untuk usaha budi daya.

Usaha akuakultur akan berhasil baik pada $\mathrm{pH}$ 6,5-9,0. Ikan akan lambat pertumbuhannya pada $\mathrm{pH}$ di bawah 6 sedangkan $\mathrm{pH} \quad 4$ dilaporkan akan menyebabkan kematian ikan (Pillay (1992).

Menurut Kordi dan Tancung (2007), nilai pH menggambarkan seberapa besar derajat keasaman atau kebasaan suatu perairan sehingga derajat keasaman merupakan faktor yang penting dalam proses pengolahan air untuk perbaikan kualitas air. Kondisi perairan bersifat netral apabila nilai $\mathrm{pH}$ sama dengan 7 , kondisi perairan bersifat asam bila kurang dari 7, sedangkan $\mathrm{pH}$ lebih dari 7 perairan bersifat basa.

Effendi (2003) menyatakan bahwa sebagian besar biota akuatik peka terhadap perubahan $\mathrm{pH}$ dan menyukai $\mathrm{pH}$ sekitar 77,5. Apabila nilai pH $6-6,5$ akan menyebabkan keanekaragaman plankton dan hewan mikrobenthos akan menurun. Sedangkan sebaran nilai $\mathrm{pH}$ pada penelitian ini adalah 5,10 - 7,17. Maka secara umum dari hasil diatas dapat disimpulkan bahwa kondisi lingkungan akuakultur pada DAS Tondano di Kelurahan Ternate Baru Kota Manado sudah berada dalam kondisi tidak layak lagi untuk kegiatan budi daya ikan. 


\section{KESIMPULAN}

Berdasarkan evaluasi hasil penelitian terhadap pengukuran parameter kualitas air di DAS Tondano Kelurahan Ternate Kota Manado dapat disimpulkan bahwa kondisi lingkungan berupa DO (2,14 - 5,70 mg/L), pH (5,10 - 7,17) dan Kekeruhan (30,2-30,80 NTU) masih berada dalam kondisi cukup layak untuk usaha budi daya ikan.

\section{DAFTAR PUSTAKA}

Boyd CE. 1982. Water Quality Management in Fish Pond Culture. Research and Development. Auburn University. Alabama. USA. 359 p.

Connell DW, Miller GJ. 1995. Penerjemah Yanti Kosasih. Kimia dan Ekotoksikologi Pencemaran.. Penerbit Universitas Indonesia. 520 hal.

Effendi H. 2003. Telaah Kualitas Air Bagi Pengelolaan Sumber Daya dan Lingkungan Perairan. Penerbit Kanisius. Yogyakarta. 258 hal.

Fardiaz S. 1992. Polusi Air dan Udara, Penerbit Kanisius, Yogyakarta. Hal : 21-23, 185.

Fardiansyah D. 2011. Perikanan Budidaya Propinsi Sulawesi Utara. Direktorat Jenderal Perikanan Budidaya, Kementrian Perikanan dan Kelautan RI. Jakarta.

Horne AJ, Goldman CR. 1983. Limnology. Mc. Graw Hill. International Book Company. Tokyo. 576 pp.

Indarto, 2010. Hidrologi Dasar Teori dan Contoh Aplikasi Model Hidrologi. PT Bumi Aksara. Jakarta.
Kordi MGHK, Tancung AB. 2007. Pengelolaan Kualitas Air Dalam Budi Daya Perairan. Penerbit Rineka Cipta. 210 hal.

Kordi MGHK. 2008. Budi Daya Perairan Buku Kesatu. PT Citra Aditya Bakti. 444 hal.

Lensun M, Tumembouw S. 2013. Tingkat Pencemaran Air Sungai Tondano di Kelurahan Ternate Baru Kota Manado. Budidaya Perairan. Vol 1 No.2: 43-48.

Onibala D. 2008. Kajian Potensi Sumberdaya Air Sungai Tondano untuk DMI dan Energy. (Thesis). Manejemen Sumberdaya Air. Institut Teknologi Bandung. Bandung.

Hhtp://digilib.itb.ac.id/gdl.php?mo d`browse\&op-read7id-jbptibppgdl-djoigenoid-31371 (diunduh tgl. 12 Januari 2015).

Rompas RM, Masengi K, Pangemanan, $\mathrm{NP}$, Moningkey R, Kawung $\mathrm{N}$. 1995. Ekologi Danau Tondano. Laporan Penelitian Fakultas Perikanan UNSRAT. Proyek Penelitian Kawasan Kritis DAS Tondano Tahun Anggaran 1995/1996 Kabupaten Minahasa. Manado.

Rompas RJ. 2002. Pengukuran Parameter Fisika-Kimia Pada Budidaya Karamba Di Sungai Tondano, Kelurahan Ternate, Kota Manado. EKOTON Vol. 2, No. 1: 13-16. PPLH-SDA. UNSRAT. Manado.

Rukmini, 2012. Teknologi Budi Daya Biota Air. Karya Putra Darwati. Bandung. 358. 
Pillay TVR. 1992. Aquaculture and The Environment. Fishing News Books. England. 189 pp.

Wetzel RG. 1983. Limnology. Saunders College Publishing. 760 pp.
Zonneveld N, Huisman EA, Boon JH. 1991. Prinsip-Prinsip Budidaya Ikan. Gramedia Pustaka Utama. Jakarta. 318 hal 